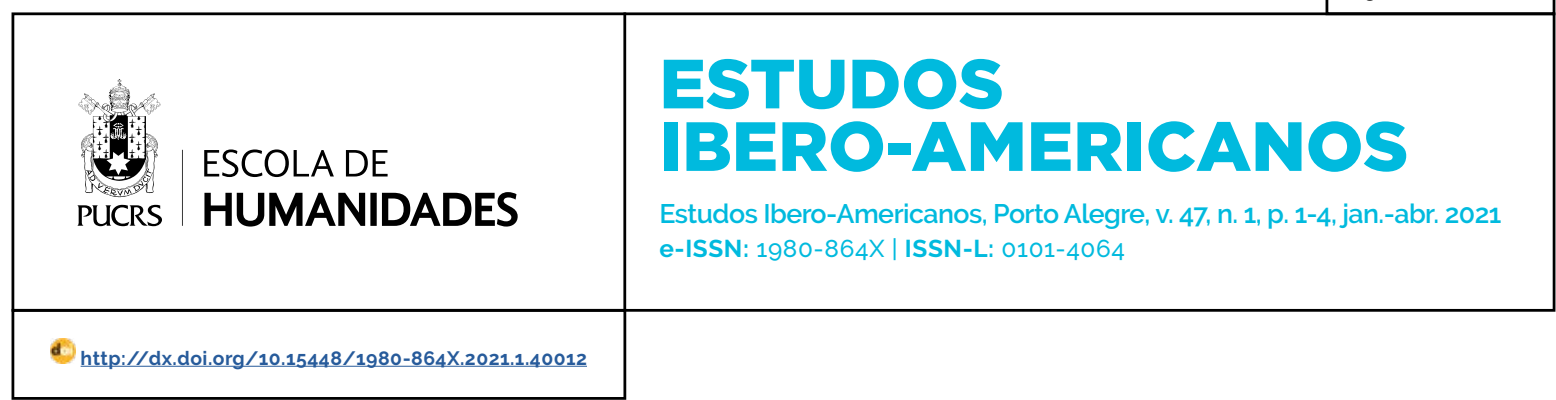

SEÇÃO: APRESENTAÇÃO DO DOSSIÊ

\title{
História das Mulheres, das relações de gênero e das sexualidades dissidentes
}

History of Women, gender relations and dissident sexualities

Historia de las Mujeres, de las relaciones de género y de las sexualidades disidentes

\section{Joana Maria Pedro \\ orcid.org/0000-0001-5690-4859 \\ joanamaria.pedro@gmail.com}

\section{Pilar Domínguez Prats ${ }^{2}$ \\ orcid.org/0000-0002-8829-2508 \\ dominguezprats@gmail.com}

Recebido em: 25/01/2021. Publicado em: 30/04/2021.

\section{(c) (1)}

Artigo está licenciado sob forma de uma licença Creative Commons Atribuição 4.0 Internacional.
A pesquisa sobre História das Mulheres, relações de gênero e sexualidades dissidentes da cisheteronormatividade vem rendendo muitos textos publicados na forma de livros, capitulos e artigos. Essa trajetória de pesquisa que, em 1989, rendeu o primeiro dossiê intitulado "A mulher no espaço público", publicado na Revista Brasileira de História e organizado por Maria Stella Martins Bresciani, ${ }^{3}$ tem crescido significativamente, ampliando seus debates, incorporando novas discussões e enfrentando novos desafios.

Quando fomos convidadas a propor uma chamada de artigos para o dossiê, sabíamos que havia no campo uma grande quantidade de resultados merecendo ser divulgados. Foi com agradável surpresa que recebemos 43 artigos. Desses, 12 estavam fora das normas e foram devolvidos; e 31 foram enviados para avaliação. Da lista dos que tiveram pareceres ad hoc favoráveis, escolhemos apenas 12, como constava das regras da revista.

Essa experiência foi gratificante, mas nos causou preocupação. Muitos artigos com grande qualidade e bons pareceres não puderam ser publicados aqui, nesse dossiê. No entanto, demonstram a potencialidade do campo, resultado de recursos investidos na pesquisa, especialmente entre $2005 \mathrm{e}$ 2016, da criação de grupos de estudos nas universidades e da vitalidade de movimentos sociais. Mostra, também, que a chamada "onda conservadora" antifeminista e homofóbica na América Latina, apesar dos seus ganhos eleitorais, não tem conseguido implantar seu "pânico moral"4 na academia. Ao contrário, observa-se resistência, crescimento e diversificação.

Os artigos escolhidos para publicação neste dossiê se concentram, principalmente, na discussão sobre História das Mulheres. Apenas um dos artigos focalizou as sexualidades dissidentes da cisheteronormatividade. Pelo menos três artigos fizeram balanços historiográficos. $\mathrm{O}$ debate com a mídia, tendo como fontes livros, novelas e jornais, foi

BRESCIANI, Maria Stella Martins (org.). A Mulher no Espaço Público. Revista Brasileira de História, São Paulo, v. 9, n. 18, p. 7-8, ago./ set. 1989 .

4 MISKOLCl, Richard; CAMPANA, Maximiliano. "Ideologia de gênero": notas para a genealogia de um pânico moral contemporâneo. Sociedade e Estado, Brasília, v. 32, n. 3, p. 725-744, set./dez. 2017. 
o principal suporte para a discussão sobre as subjetividades e a prescrição de normas para mulheres em diferentes momentos.

Abrindo o dossiê, o artigo "Relações de gênero, capitalismos afetivos, literatura 'Chick-lit/Soft Porn' e a 'nova' escrita contemporânea de/para mulheres", escrito por Ana Carolina Eiras Coelho Soares, focaliza a literatura recente, sucesso de vendas, voltada para mulheres. A autora mostra como, apesar de essa literatura partir do pressuposto de que o prazer no sexo é um direito das mulheres, muitas imagens antigas são revisitadas. Nos pares que se formam, nessa literatura, os homens são sempre brancos, bem-sucedidos profissionalmente e muito mais ricos que as mulheres. Essas, possuem empregos insignificantes e nunca têm carreiras de sucesso. Elas se submetem "livremente" aos desejos do homem, por mais violentos que esses sejam. Uma cinderela contemporânea?

Raquel de Barros Pinto Miguel, no artigo "Fotonovelas: prescrevendo normas, modos e modas", analisou as fotonovelas publicadas na revista Capricho nas décadas de 1950 e 1960. Nelas, as mocinhas, em geral pobres e órfãs, sofriam até encontrar a felicidade, casando-se com homem rico e lindo. A autora analisa essa "literatura de escape" e mostra o sucesso que obteve, observando a constituição das subjetividades engendradas.

O artigo "Modernidad, cultura y vanguardia feminista: Concha Méndez, una adelantada a su tiempo. De la voluntad emancipadora al exilio trasatlántico", de Esmeralda Broullón, trata de analisar a trajetória pessoal e cultural da poetisa da geração de 1927, Concha Méndez, destacando o seu papel como escritora, editora e promotora cultural na Espanha nos anos 1920 e 1930, juntamente com o conhecido poeta Manuel Altolaguirre. Enfoca o período caracterizado pela grande efervescência política, pelo avanço do feminismo no país ibérico e por instituições de estudos como o Lyceum Club, um influente círculo cultural do qual Concha Méndez fez parte e onde se conheceram destacadas feministas que, pouco depois, em 1931, defenderam a conquista do voto feminino. A trajetória da autora no exilio mexicano, após a derrota da república espanhola em 1939, é, também, rapidamente delineada no artigo.

As discussões que articulam gênero e decolonialidade ou, como dizem as autoras, as "perspectivas contra coloniais" estão presentes no texto de Cintia Lima Crescêncio e Gleidiane de Sousa Ferreira, intitulado "Da História das Mulheres às perspectivas Contra-Coloniais? Reflexões sobre a historiografia do gênero no Brasil (2001-2019)". Buscando, em eventos promovidos pela Associação Nacional de História (ANPUH-Brasil) e pelo Fazendo Gênero a presença da discussão contra-colonial entre pesquisadoras/es que discutem História das Mulheres e gênero, as autoras constatam que esse é um tema iniciante e com pouca presença, o que demonstra um pouco de resistência do campo da historiografia para essa questão.

Utilizando com principal fonte o periódico argentino Brujas, Júlia Glaciela da Silva Oliveira, no artigo "'Sin senderos prefijados': a defesa da autonomia feminista nas páginas de Brujas (1981-1996)", discute a autonomia do movimento feminista. Além de apresentar a historicidade desse debate nos anos 1970, a autora articula o tema com o avanço neoliberal na América Latina.

Também usando periódicos como a principal fonte, o artigo "As mulheres e suas tramas impressas: um repensar historiográfico das produções sobre a sociedade carioca e portenha dos anos iniciais da segunda metade do século XIX", escrito por Bárbara Figueiredo Souto, mostra como a historiografia da imprensa e a que focaliza intelectuais ainda não deu a devida visibilidade às mulheres que escreveram e dirigiram periódicos em Buenos Aires e no Rio de Janeiro no século XIX. No artigo, Joanna Paula Manso de Noronha, por sua trajetória como editora e escritora, tanto na Argentina como no Brasil, é classificada como uma intelectual-mediadora-feminista-transnacional.

Patrícia Lessa e Claudia Maia, no artigo "Feminismo, vegetarianismo e antivivisseccionismo em Maria Lacerda de Moura", trazem do início do século XX uma discussão que tem ganhado força neste início do século XXI: o antiespecismo. No caso de Maria Lacerda de Moura, tratava-se de um feminismo que se articulava com a questão da classe, com a luta pelo vegetarianismo e 
contra a vivissecção. Importante destacar como questões que hoje ganham destaque eram alvo de discussões e de publicações por Maria Lacerda de Moura e, no entanto, ficaram esquecidas.

O artigo "Algunas reflexiones sobre género y memoria en las narrativas sobre los años setenta en Argentina", de Ana Laura Noguera, levanta questões importantes sobre a memória e a História do Tempo Presente na Argentina. A autora aponta as discussões teórico metodológicas que articulam gênero e memória na história recente. Mostra a importância da história oral para a pesquisa em História das Mulheres e do Gênero. Destaca, também, a forma como homens e mulheres narram suas histórias de vida e o impacto historiográfico das diferentes histórias para a noção de agência.

Caroline Pereira Leal, no artigo "'Mais bela do que o sol, mais bela do que o céu': representação feminina no discurso carnavalesco da Porto Alegre do início do século XX (1906-1914)", nos leva de volta ao início do século passado para mostrar as tentativas de definir, nas elites e com repercussões duvidosas, como deveriam se comportar as mulheres nas festas de carnaval.

O artigo "Memória em disputa: Inah Costa e os desafios da história das mulheres artistas", escrito por Rebecca Corrêa e Silva, discute a invisibilidade, as dificuldades e o impacto do gênero na vida das mulheres que atuam no campo da arte. Ela traz a história de uma artista que passou da pintura figurativa para a moderna e abstrata.

O único artigo que discute sexualidades dissidentes é o de Marina Leitão Mesquita, intitulado "Gênero, dissidência e tradição na (re)invenção da feminilidade em concursos de beleza gay". Trata-se de uma etnografia sobre concursos de beleza gay em Fortaleza, Ceará. A discussão sobre as hierarquias, formas de feminilidades aceitas, assim como a memória de momentos em que a polícia interferia, marcam a narrativa. A discussão sobre a "feminilidade espetacular", como padrão de beleza, ajuda a questionar as configurações de gênero.

O artigo de Maria Laura Osta Vázquez, intitulado "Manos que mecen la cuna: las nodrizas uruguayas bajo el control del discurso médico en el siglo XIX", mostra o fim de uma profissão assumida por muitas mulheres pobres, negras, mestiças e estrangeiras: as amas de leite. Na segunda metade do século XIX, o discurso médico passou a questionar as mulheres que entregavam seus filhos para amas de leite e a discutir a saúde e a moral dessas profissionais. Toda essa campanha foi feita pela imprensa e pelo discurso médico higienista que - em nome da redução da mortalidade infantil - passou a cobrar das mulheres o "amor materno".

Temos a honra que encerrar este dossiê com a entrevista de Maria Odila Leite da Silva Dias, professora emérita da Universidade de São Paulo (USP). Autora, entre outros, do livro Quotidiano e Poder, que abriu caminhos para a história das mulheres no Brasil, focalizando mulheres pobres, escravizadas e forras nas suas lidas para prover a existência no início do século XIX, ela é responsável pela formação de pesquisadoras que trouxeram inúmeras contribuições para o campo da História das Mulheres, do gênero e das sexualidades dissidentes.

\section{Boa leitura.}

\section{Joana Maria Pedro}

Doutora em História Social pela Universidade de São Paulo (USP), em São Paulo, SP, Brasil; pós-doutora na França, na Université d'Avignon e, também, nos Estados Unidos, na Brown University; professora titular da Universidade Federal de Santa Catarina (UFSC), em Florianópolis, SC Brasil. Coordenadora do Instituto de Estudos de Gênero (IEG), Florianópolis/SC, Brasil. Atuou como Presidenta da Associação Nacional de História (ANPUH), na gestão 2017-2019.

\section{Pilar Domínguez Prats}

Doctora en Historia por la Universidad Complutense de Madrid (UCM), en Madrid, España. Profesora honorifica del área de Historia del Pensamiento Político y Movimientos Sociales de la Universidad de Las Palmas de Gran Canaria, España. En la actualidad es investigadora del proyecto: Redes de Cooperación Interuniversitaria Canarias-Africa en Politicas de Igualdad desde metodologias colaborativas" y del Centro de Estudios y Difusión del Atlántico, CEDA. Socia fundadora del Seminario de Fuentes Orales de la Universidad Complutense de Madrid y del Instituto de Investigaciones Feministas de la UCM; presidenta de la Asociación Internacional de Historia Oral, IOHA (2008-2010) y miembro del Consejo de IOHA (2004 a 2012). 
$4 / 4$ Estudos Ibero-Americanos, Porto Alegre, v. 47, n. 1, p. 1-4, jan.-abr. 2021 | e-40012

\section{Endereço para correspondência}

Joana Maria Pedro

Rua Deputado Antônio Edu Vieira, 1304, bloco B, apto. 101

88040-001

Florianópolis, Santa Catarina, Brasil

Pilar Dominguez Prats

Paseo Sta Maria de la Cabeza 1, 5 dcha. 28045

Madrid, España 